

\title{
Assessment of Structural Feature and Ionic Diffusivity of ITZ in Blended Cementitious Composites
}

\author{
Yun $\mathrm{Gao}^{1 *}$, Geert De Schutter ${ }^{2}$, Guang Ye ${ }^{3}$, Jinyang Jiang ${ }^{4}$ and Wei Sun ${ }^{5}$
}

\begin{abstract}
In this paper, we present a study about the assessment of structural feature and ionic diffusivity of interfacial transition zone (ITZ) in blended cementitious composites, which are made of Portland cement, blast furnace slag and limestone filler. In particular, three mortar series are examined with respect to varying replacement levels of supplementary cementitious materials (SCMs), curing age and water-to-binder (w/b) ratio. Based on the techniques of experimental measurement and numerical simulation, i.e., the backscattered electron (BSE) image analysis and the HYMOSTRUC model, the structural features of ITZ in designed mortars are elaborated in a quantitative manner. Thereafter, a lattice Boltzmann method based computer modeling of ionic diffusion in the ITZ is performed to predict the ionic diffusivity. Results indicate that the ITZ differs much from bulk paste, which is of significant importance in blended cementitious composites. The structural feature and the ionic diffusivity of ITZ are prominently affected by various casting factors, such as replacement levels of SCMs, curing age and w/b ratio.
\end{abstract}

\section{Introduction}

It is well known that cementitious composites are of intrinsic heterogeneity, which typically consist of a wide range of structural features from nanometer-sized gel pores to centimeter-sized aggregates (Maekawa et al. 2003). In engineering practices, two structural scales are often defined in characterizing the microstructure of cementitious composites, i.e., the pore scale and the paste scale. In particular, the pore scale refers to the phase components of cement paste including anhydrous grains, hydration products and capillary pores, while the paste scale refers to the phase components of mortar/concrete including aggregate, the interfacial transition zone (ITZ) and bulk paste. Herein, the ITZ is a special phase which exists between aggregate and bulk paste (Scrivener $e$ t al. 2004). Moreover, it is generally believed that the ITZ

${ }^{1}$ Assistant Professor, School of Materials Science and Engineering, Southeast University, Nanjing, People's Republic of China.

*Corresponding author, E-mail: gaoyun3888@126.com

${ }^{2}$ Professor, Magnel Laboratory for Concrete Research, Department of Structural Engineering, Ghent University, Ghent, Belgium.

${ }^{3}$ Associate Professor, Delft University of Technology, Delft, the Netherlands and Visiting Professor, Magnel Lab for Concrete Research, Department of Structural Engineering, Ghent University, Belgium.

${ }^{4}$ Professor, School of Materials Science and Engineering, Southeast University, Nanjing, People's Republic of China.

${ }^{5}$ Professor, School of Materials Science and Engineering, Southeast University, Nanjing, People's Republic of China. displays a significant excess of porosity in conventional mortar/concrete, which makes it a weak link. For its critical importance to the overall property of cementitious composites, the ITZ has drawn much attention during past decades (Shane et al. 2000; Sun et al. 2011).

Being one of the most widely used construction materials, the production of concrete has to consume a huge amount of natural resource and energy annually, which exerts severe pressure on the environment. Besides, as the society progresses fast, a higher requirement necessitates for the durability of infrastructures. In order to solve these problems, some new types of cementitious composites have been developed in recent decades, which make use of industrial byproducts as supplementary cementitious materials (SCMs) to partially replace cement (Mehta 1998; Lothenbach et al. 2011). On one hand, the usage of SCMs is quite beneficial to the environmental protection; on the other hand, many studies have indicated that the incorporation of SCMs can even contribute to considerable improvements on the durability of cementitious composites. For instance, the blast furnace slag blended concrete is found to be more durable when subjected to aggressive environments (Osborne 1999). Because of these advantages, researchers have spent tremendous efforts on investigating the characteristics of blended cementitious composites (Shannag 2000; Yoon et al. 2002). Nevertheless, relevant researches on the quantification of structural features as well as the ionic diffusivity of ITZ are somewhat insufficient for blended cementitious composites, since it is of critical importance to the durability (Prokopski and Halbiniak 2000; Gao et al. 2005). In this paper, we intend to present some results about a quantitative assessment of structural feature and ionic diffusivity of ITZ in blended cementitious composites, where the effects of various casting factors are discussed, such as replacement levels 
Table 1 Chemical composition and physical properties of binder materials.

\begin{tabular}{llll}
\hline $\begin{array}{l}\text { Chemical composition and } \\
\text { physical properties }\end{array}$ & Cement & Slag & Filler \\
\hline Calcium oxide $(\mathrm{CaO}, \%)$ & 63.37 & 41.83 & ---- \\
Silica $\left(\mathrm{SiO}_{2}, \%\right)$ & 18.90 & 36.32 & 0.80 \\
Alumina $\left(\mathrm{Al}_{2} \mathrm{O}_{3}, \%\right)$ & 5.74 & 10.72 & 0.17 \\
Iron oxide $\left(\mathrm{Fe}_{2} \mathrm{O}_{3}, \%\right)$ & 4.31 & 0.21 & 0.10 \\
Magnesium oxide $(\mathrm{MgO}, \%)$ & 0.89 & 8.97 & 0.50 \\
Potassium oxide $\left(\mathrm{K}_{2} \mathrm{O}, \%\right)$ & 0.73 & 0.37 & ---- \\
Sodium oxide $\left(\mathrm{Na}_{2} \mathrm{O}, \%\right)$ & 0.47 & 0.27 & ---- \\
Sulfur trioxide $\left(\mathrm{SO}_{3}, \%\right)$ & 3.34 & 0.94 & ---- \\
Calcium carbonate $\left.(\mathrm{CaCO})_{3}, \%\right)$ & ---- & ---- & 98.0 \\
Insoluble residue $(\mathrm{IS}, \%)$ & 0.41 & 0.25 & ---- \\
Loss on ignition $(\mathrm{LOI}, \%)$ & 1.51 & 0.76 & ---- \\
\hline Blaine fineness $\left(\mathrm{m}^{2} / \mathrm{kg}\right)$ & 353 & 469 & 753 \\
Specific density $\left(\mathrm{kg} / \mathrm{m}^{3}\right)$ & 3120 & 2896 & 2650 \\
\hline
\end{tabular}

Table 2 Physical properties of the sand aggregate used in mortar specimens.

\begin{tabular}{cc}
\hline Mass density & $2567 \mathrm{~kg} / \mathrm{m}^{3}$ \\
\hline Specific surface area & $7.63 \mathrm{~m}^{2} / \mathrm{kg}$ \\
\hline Water adsorption & $0.201 \mathrm{~g} / \mathrm{g}$ \\
\hline
\end{tabular}

of SCMs, curing age and water-to-binder (w/b) ratio.

A brief introduction on the structure of this paper is given as follows. Section 2 presents the details of experimental measurement, i.e., the backscattered electron (BSE) image analysis. In Section 3, the numerical simulation with respect to the ITZ is introduced, where the wall effect and the local $\mathrm{w} / \mathrm{b}$ ratio are taken into account. Thereafter, a fitting function is applied to determine the ITZ extent in Section 4. Section 5 presents a computer modeling of ionic diffusion in the ITZ. The discussions of effects for various casting factors including replacement levels of SCMs, curing age and $w / b$ ratio are presented in Section 6. Some concluding remarks drawn from this study are given in Section 7.

\section{Experimental measurement of ITZ}

\subsection{Specimen preparation}

According to the chemical reactivity, two types of SCMs are often classified in practice, i.e., reactive and inert SCMs. For instance, blast furnace slag which can react with calcium hydroxide is classified as reactive SCMs, while limestone powder which displays a low chemical reactivity is classified as inert SCMs. In this study, ternary blended mortars are designed, which are made of Portland cement (cement), blast furnace slag (slag) and limestone filler (filler). Chemical compositions and physical properties of binder materials are listed in Table $\mathbf{1}$, and the particle size distributions are shown in Fig. 1. Ordinary river (quartz) sands are mixed as aggregates and the relevant physical properties are listed in Table 2.

Three series of mortar specimens are cast with regard to replacement levels of SCMs, curing age and w/b ratio. Details about the mix proportions are listed in Tables 3-5. In particular, the mortar series A is to study the effect of replacement levels of SCMs, where the reactive slag
Table 3 Mix proportion of mortar series A.

\begin{tabular}{|c|c|c|c|c|c|c|}
\hline \multirow{2}{*}{ Mortar } & \multicolumn{3}{|c|}{ Mass fraction in binder } & \multirow{2}{*}{$\begin{array}{c}\text { Curing } \\
\text { age }\end{array}$} & \multirow{2}{*}{$\begin{array}{l}\mathrm{w} / \mathrm{b} \\
\text { ratio }\end{array}$} & \multirow{2}{*}{$\begin{array}{c}\text { Sand } \\
\text { content }\end{array}$} \\
\hline & Cement & Slag & Filler & & & \\
\hline A1 & $60 \%$ & $0 \%$ & $40 \%$ & \multirow{3}{*}{$56 \mathrm{~d}$} & \multirow{3}{*}{0.4} & \multirow{3}{*}{$10 \%$} \\
\hline A2 & $60 \%$ & $20 \%$ & $20 \%$ & & & \\
\hline A3 & $60 \%$ & $40 \%$ & $0 \%$ & & & \\
\hline
\end{tabular}

Table 4 Mix proportion of mortar series B.

\begin{tabular}{|c|c|c|c|c|c|c|}
\hline \multirow{2}{*}{ Mortar } & \multicolumn{3}{|c|}{ Mass fraction in binder } & \multirow{2}{*}{$\begin{array}{c}\text { Curing } \\
\text { age }\end{array}$} & \multirow{2}{*}{$\begin{array}{l}\mathrm{w} / \mathrm{b} \\
\text { ratio }\end{array}$} & \multirow{2}{*}{$\begin{array}{c}\text { Sand } \\
\text { content }\end{array}$} \\
\hline & Cement & Slag & Filler & & & \\
\hline B1 & \multirow{3}{*}{$60 \%$} & \multirow{3}{*}{$20 \%$} & \multirow{3}{*}{$20 \%$} & $28 \mathrm{~d}$ & \multirow{3}{*}{0.4} & \multirow{3}{*}{$10 \%$} \\
\hline B2 & & & & $56 \mathrm{~d}$ & & \\
\hline B3 & & & & $90 \mathrm{~d}$ & & \\
\hline
\end{tabular}

Table 5 Mix proportion of mortar series C.

\begin{tabular}{|c|c|c|c|c|c|c|}
\hline \multirow{2}{*}{ Mortar- } & \multicolumn{3}{|c|}{ Mass fraction in binder } & \multirow{2}{*}{$\begin{array}{c}\text { Curing } \\
\text { age }\end{array}$} & \multirow{2}{*}{$\begin{array}{l}\mathrm{w} / \mathrm{b} \\
\text { ratio }\end{array}$} & \multirow{2}{*}{$\begin{array}{c}\text { Sand } \\
\text { content }\end{array}$} \\
\hline & Cement & Slag & Filler & & & \\
\hline $\mathrm{C} 1$ & \multirow{3}{*}{$60 \%$} & \multirow{3}{*}{$20 \%$} & \multirow{3}{*}{$20 \%$} & \multirow{3}{*}{$56 \mathrm{~d}$} & 0.3 & \multirow{3}{*}{$10 \%$} \\
\hline $\mathrm{C} 2$ & & & & & 0.4 & \\
\hline $\mathrm{C} 3$ & & & & & 0.5 & \\
\hline
\end{tabular}

content increases from $0 \%, 20 \%$ to $40 \%$, while the inert filler content decreases from $40 \%, 20 \%$ to $0 \%$ in correspondence. The mortar series B is to study the effect of curing age, i.e., from 28,56 to 90 days. The mortar series $\mathrm{C}$ is to study the effect of $\mathrm{w} / \mathrm{b}$ ratio, i.e., from $0.3,0.4$ to 0.5. Mortars A2, B2 and C2 are actually the same. The use of different symbols is for the sake of comparison.

After sufficient mixing, mortars were cast in cubic moulds $\left(10 \times 10 \times 10 \mathrm{~cm}^{3}\right)$, which were vibrated on a vibration table around 2 minutes. The fresh mortars were stored in a curing room $(95 \% \pm 10 \%$ relative humidity and $20^{\circ} \mathrm{C} \pm 1^{\circ} \mathrm{C}$ temperature). After 24 hours, mortars were demoulded and cured in above mentioned curing room until the designed age.

\subsection{Experimental investigation}

For its advantage in quantification of structural features, the BSE image analysis is applied. The following procedures were employed to acquire qualified BSE images. First of all, specimens were drilled at the end of curing.

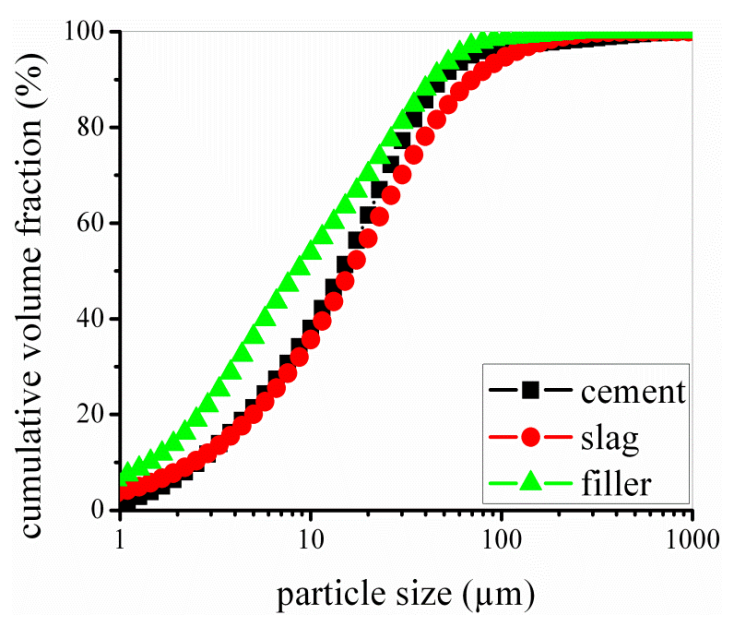

Fig. 1 Particle size distributions of raw materials for designed mortars. 
The acquired core parts ( $6 \mathrm{~cm}$ of diameter from center $)$ were sawn perpendicular to the casting direction and split into small pieces (around $5 \mathrm{~cm}^{3}$ ). Thereafter, the collected pieces were immersed in liquid nitrogen about five minutes to stop hydration. Low temperature vacuum freeze drying was then applied for one week. The dry specimens were impregnated with epoxy resin and cured in an oven at $40^{\circ} \mathrm{C}$ for 24 hours. Since the penetration depth of epoxy resin was often very small, the impregnated samples were sawed to expose a flat surface. Afterwards, the samples were impregnated a second time. Then, the samples were ground with $\mathrm{SiC}$ paper 320,500 , 1200 and 2400 grit for about 2 minutes each. Finally, the samples were polished with diamond paste of 3,1 and $0.25 \mu \mathrm{m}$ for about 2 minutes each and cleaned up with a low-relief polishing cloth.

The polished samples were examined under the BSE detector in the environmental scanning electron microscope with an acceleration voltage of $20 \mathrm{kV}$. Images were captured around aggregates randomly. No more than two images were taken for each aggregate. Two magnifications were applied, i.e., $100 \times$ and 500×. Herein, the $100 \times$ images are adopted for qualitative comparisons, while the 500× images are adopted for quantitative comparisons. For each type of mortar, 30 frames of $500 \times$ images were collected, with the physical resolution of

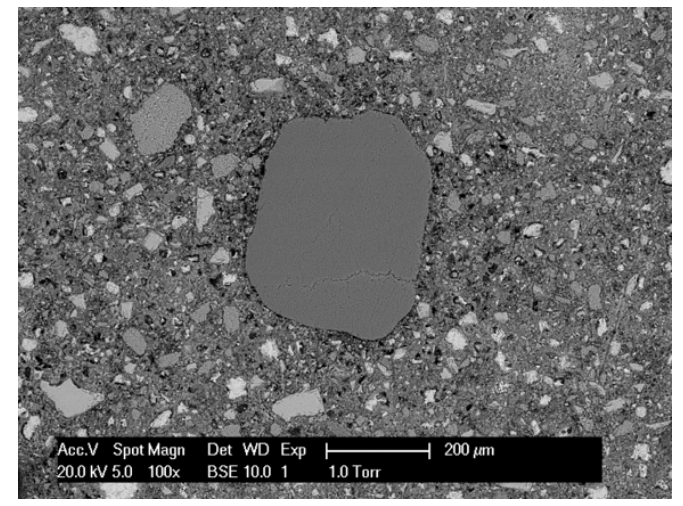

(a) $100 \times$ BSE image
$0.18 \mu \mathrm{m}$ and the dimension of $1424 \times 968$ in pixel units. As shown in Fig. 2, a porous zone in the vicinity of aggregate surface can be detected.

BSE images of cementitious composites are random arrangements of capillary pores, hydration products and anhydrous grains. Thus, an appropriate image analysis method necessitates. In this paper, the used image analysis consists of concentric expansion for strip delineation and overflow criterion for phase segmentation. The concentric expansion for strip delineation finds an approximate center for irregular aggregate based on the least square method, and then imposes a concentric expansion on original boundary of aggregate. The overflow criterion for phase segmentation considers cumulative histogram of grey scales of BSE image, and then determines the intercept of two detectable slopes. More details are referred to (Gao et al. 2013a; Gao et al. 2013b).

The component profiles are shown in Fig. 3, i.e., area fractions of capillary pores and anhydrous grains. Throughout this paper, anhydrous grains include all binder grains, i.e., cement, slag and filler.

\section{Numerical simulation of ITZ in blended cementitious composites}

For the current ternary blended system, the hydration

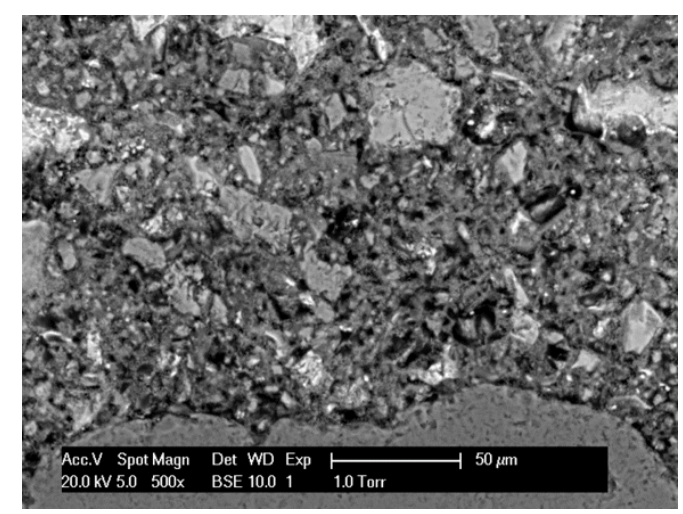

(b) $500 \times$ BSE image

Fig. 2 Acquired BSE image examples adopted from the mortar A2.

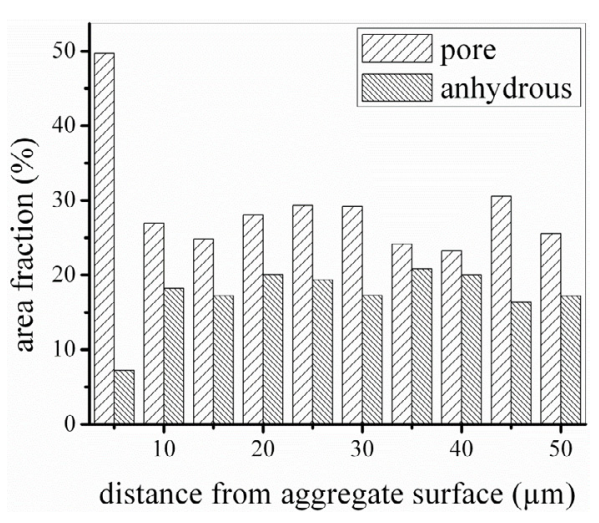

(a) Component profiles from 0 to $50 \mu \mathrm{m}$

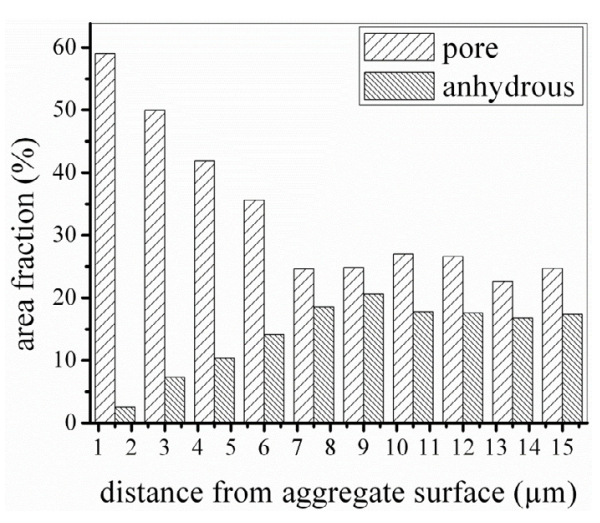

(b) Component profiles from 0 to $15 \mu \mathrm{m}$

Fig. 3 Component profiles obtained from BSE image analysis. 
process is much more complex than plain cement system, where the hydration of slag and filler has to be considered as well. As studied, the hydration products of cement blended with slag are essentially similar to those of plain cement, i.e., calcite silicate hydrate $(\mathrm{CSH})$ and calcium hydroxide (CH) (Richardson 2008; Luan et al. 2012). The hydration of slag also goes through three stages: the nucleation period during which product growth is accelerating, the phase boundary controlled stage and the diffusion-controlled stage. As for limestone filler, two sided effects have been reported. On one hand, if only, the chemical reactivity of limestone filler is very low; on the other hand, it speeds up the early age hydration process. In this study, we employ a numerical model to simulate the microstructure of current ternary blended system, i.e., the HYMOSTRUC model. In particular, spherical binder grains are assumed and the rate of hydration and the formation of inter-particle contacts are modeled as a function of particle size distribution, chemical composition and reaction temperature (van Breugel 1991). The increment of penetration depth $\Delta \delta_{i n ; x, j}+1$ for a particle with diameter $\mathrm{x}$ during a time increment $\Delta_{t j}+1=t_{j}+1-t_{j}$ equals:

$$
\begin{aligned}
& \frac{\Delta \delta_{i n ; x, j+1}^{i}}{\Delta t_{j+1}}=K_{i} \times K(A) \times \Omega_{1}(\cdot) \times \Omega_{2}(\cdot) \times \Omega_{3}(\cdot) \times \\
& F_{1}(T) \times\left\{F_{2}\left(\beta_{2}\right) \times\left[\frac{\delta_{t r}}{\delta}\right]^{\beta_{1}}\right\}^{\lambda}
\end{aligned}
$$

where $i=1,2$, and 3 denotes cement, slag, filler, respectively; $K_{i}$ denotes the basic rate factors of binder grains; and $K(A)$ denotes the influence of amount of SCMs. $\Omega_{1}(\cdot)$ denotes the reduction factor accounting for water withdrawal effects. $\Omega_{2}(\cdot)$ and $\Omega_{3}(\cdot)$ are the reduction factors accounting for water shortage in the pore system and for reduction of the amount of water in the hydrating mass. $F_{1}(\cdot)$ and $F_{2}(\cdot)$ are parameters taking into account the effect of the curing temperature on the rate of processes and the effect of curing temperature on morphology and formation of structure. $\lambda$ denotes the factor depending on the rate controlling mechanism. $\beta_{1}$ and $\beta_{2}$ are constants.

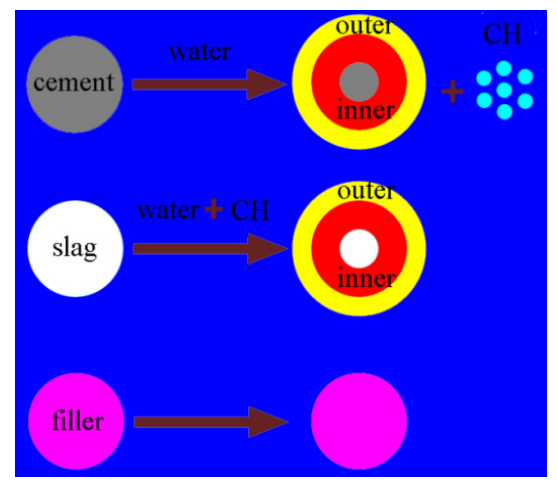

(a) Hydration of ternary system (outer: outer $\mathrm{CSH}$; inner: inner $\mathrm{CSH}$ ) $\delta_{t r}$ is the transition thickness that determines the change-over from a phase-boundary reaction into a diffusion-controlled reaction and $\delta$ is the total thickness of product surrounding anhydrous core for a cementitious particle at the end of time step $\Delta t_{j}$. The listed parameters $\left(K_{i}, \Omega_{1}(\cdot), \Omega_{2}(\cdot), \Omega_{3}(\cdot), F_{1}(\cdot), F_{2}(\cdot), \lambda, \delta, \delta_{t r}, \beta_{1}, \beta_{2}\right)$ in Eq. (1) have been well discussed (van Breugel 1991; Ye and van Breugel 2009). For blended systems, Ye introduced the additional parameter $K(A)$. In common, the presence of SCMs improves the hydration process. The quantity of $K(A)$ should be larger than 1 . Here, the value of 1.13 is taken, as suggested in (Ye and van Breugel 2009). Hydration products include inner $\mathrm{CSH}$, outer $\mathrm{CSH}$ and $\mathrm{CH}$. The volume of outer $\mathrm{CSH}$ can be calculated based on Eq. (2). Production and consumption of $\mathrm{CH}$ are estimated according to Eqs. (3)-(4), and remaining amount of $\mathrm{CH}$ is calculated by Eq. (5).

$$
\begin{aligned}
& V_{o u ; x}^{i}=\left(v^{i}-1\right) \times \alpha_{j}^{i} \times V_{x}^{i} \\
& m_{C H, p r o ; j}=\xi_{\text {hyd }} \times m^{1} \times \alpha_{j}^{1} \\
& m_{C H, c o n ; j}=\xi_{p o z z} \times m^{2} \times \alpha_{j}^{2} \\
& m_{C H ; j}=m_{C H, p r o ; j}-m_{C H, c o n ; j}
\end{aligned}
$$

where $i, j$ are defined in the same way as in Eq. (1); $V_{\text {ou; }}$ is the volume of outer $\mathrm{CSH}$ for the reactive particles; $v$ is the volume ratio of reaction product and dissolved reactant; $\alpha$ is hydration degree; $V_{x}$ is volume of single particle. $m_{C H, p r o ; j}$ is mass of $\mathrm{CH}$ produced from cement hydration, and $m_{C H, c o n ; j}$ is mass of $\mathrm{CH}$ consumed in hydration of slag; $\xi_{h y d}$ and $\xi_{p o z z}$ are the respective production and consumption coefficients with regard to CH. $\mathrm{m}^{1}$ and $\mathrm{m}^{2}$ denote initial mass of cement and slag, respectively. The volume ratio between reaction product and reactant is taken as 2.2 and 1.8 for cement and slag respectively. Eq. (3), i.e., the production of $\mathrm{CH}$, is addressed in terms of the chemical composition of cement. The mass stoichiometry of reaction is taken as $0.05 \mathrm{~g} / \mathrm{g}$ at the consumption of $\mathrm{CH}$ for slag (Saeki and Monteiro 2005). As shown in Fig. 4(a), CSH is supposed to grow in a

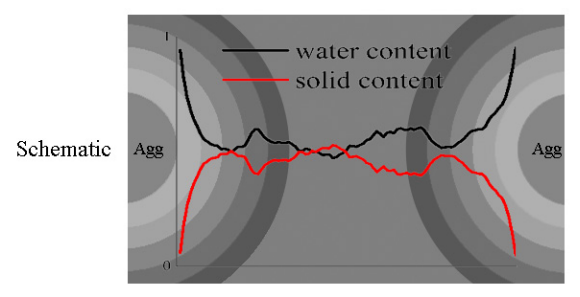

Model

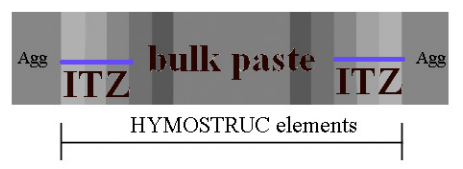

(b) Local $\mathrm{w} / \mathrm{b}$ ratio and moisture transport in HYMOSTRUC with regard to the ITZ (Agg: aggregate)

Fig. 4 Schematic illustration of numerical model to simulate the microstructure of ITZ and bulk paste in ternary blended cementitious composites. 
concentric-wise way, while $\mathrm{CH}$ is assumed to be randomly located as spheres in pore solutions. When one $\mathrm{CH}$ particle is fully embedded in hydrating particles, its position has to be re-located randomly in the pore solution.

The simulation of ITZ is processed similarly to plain cement paste. Moreover, with respect to the forming mechanism of ITZ, some specific factors have to be considered. In particular, due to the initial water content difference, grains within ITZ and bulk paste encounter different $\mathrm{w} / \mathrm{b}$ ratios. Thus, parallel elements are employed in the simulation system. The local $\mathrm{w} / \mathrm{b}$ ratio is calculated within each element and water transport is considered in neighboring elements, as illustrated in Fig. 4(b). Thereafter, water transport is estimated based on Eqs. (6)-(8).

$$
\begin{aligned}
& \frac{\partial \theta}{\partial t}=-\nabla \cdot(K \cdot \nabla p) \\
& K=\frac{\varphi^{2}}{50 B^{2} \mu}\left(1-\left(-\ln \left(1-\frac{\theta}{\varphi}\right)\right) \cdot\left(1-\frac{\theta}{\varphi}\right)\right)^{2} \\
& p=\frac{2 C B \gamma_{l v} \cos \theta_{c}}{\ln \left(1-\frac{\theta}{\varphi}\right)}
\end{aligned}
$$

where $\theta, \varphi$ is volumetric water content and porosity in

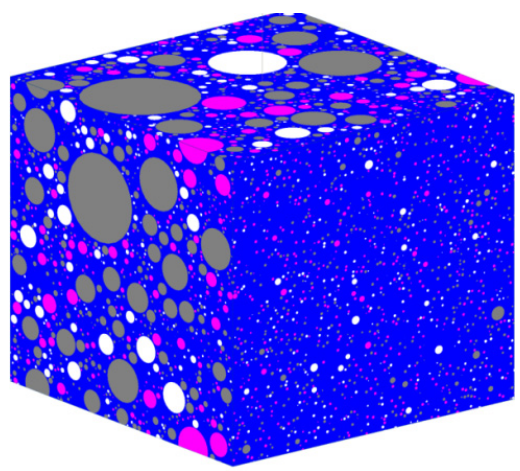

(a) Mortar A2 on mixing each element, respectively; $t$ denotes relative time step; $K$ is the water permeability of each element; $p$ is capillary suction force. In addition, $B$ denotes the Raleigh-Ritz pore size distribution constant in HYMOSTRUC; $\mu$ is the water viscosity; $\gamma_{l v}$ denotes the liquid-vapor interfacial energy; $\theta_{c}$ is the equilibrium contact angle between liquid and solid. For parameters in Eqs. (7)-(8), $B, \mu, \gamma_{l v}$ and $\theta_{c}$ are set as $3.6 \times 10^{7} \mathrm{~m}^{-1}, 0.001 \mathrm{~Pa} \cdot \mathrm{s}, 0.0728 \mathrm{~N} / \mathrm{m}$ and $25^{\circ}$ (Maekawa et al. 2009; Zhou 2011; Huang and Ye 2012; Aligizaki 2006). $C$ is the constant, and the value of 2.15 is utilized (Maekawa et al. 2009).

An example of the simulated microstructure is shown in Fig. 5, which is implemented in a cubic system of $100 \times 100 \times 100 \mu \mathrm{m}^{3}$. As seen, due to the wall effect, at the interfacial face between aggregate and cement paste, the initial porosity is much higher than further out. After 56 days, the relevant porosity decreases remarkably.

The component profiles can also be computed, i.e., area fractions of capillary pores and anhydrous grains. As shown in Fig. 6, the gradual increasing anhydrous fraction and decreasing porosity can be detected. For instance, at the interfacial face, the porosity decreases from $95 \%$ to $65 \%$ after 56 days of curing.

\section{The determination of ITZ extent}

Since no discrete boundary exists between ITZ and bulk paste, the criterion to determine ITZ extent is of impor-

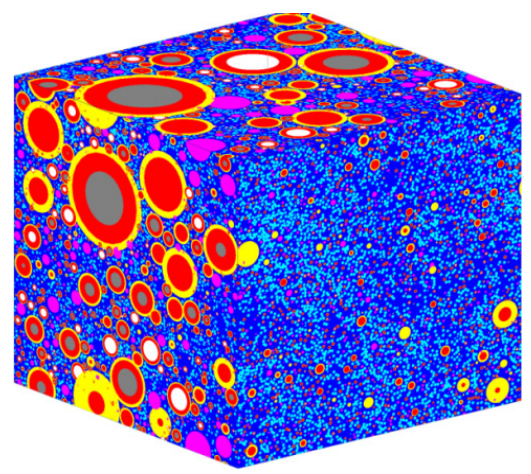

(b) Mortar A2 hydrated at 56 days

Fig. 5 Simulated microstructure of ITZ and bulk paste, front and back faces are solid boundaries representing aggregates.

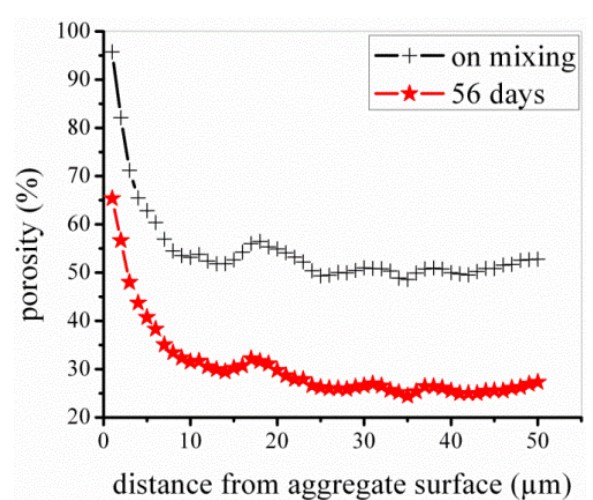

(a) Area fraction profile of capillary pores

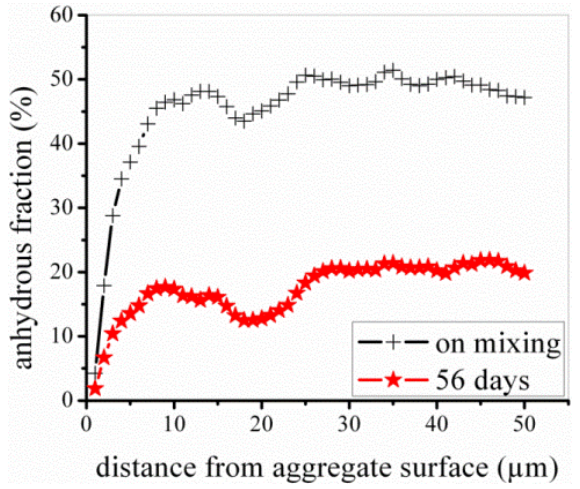

(b) Area fraction profile of anhydrous grains

Fig. 6 Component profiles computed from the simulated microstructure of mortar A2. 
tance. A modified power law function is applied to fit the porosity profile starting aggregate surface, which incorporates the ITZ extent as a parameter (Lutz et al. 1997; Gao et al. 2014),

$$
\varphi(x)=\varphi_{i f}-\left(\varphi_{i f}-\varphi_{b u l k}\right)\left(\frac{x}{d}\right)^{\beta}
$$

where $\varphi(x)$ is the porosity at the location with distance $x$ to the aggregate surface; $\varphi_{i f}$ is the porosity at the interfacial face, i.e., the contacting face between cement paste and aggregate; $\varphi_{\text {bulk }}$ is the porosity of bulk paste; $d$ is the ITZ extent; $\beta$ is the fitting parameter. A schematic illustration of is indicated in Fig. 7.

To apply Eq. (9), the value of $\varphi_{\text {bulk }}$ has to be determined firstly. Herewith, $\varphi_{\text {bulk }}$ takes the stable value of porosity far from aggregate surface. Results of the mortar A2 are listed in Table 6, which are fitted from the simulated porosity profile. Moreover, for the mortar A2, the simulated microstructures of ITZ and bulk paste can be obtained, as shown in Fig. 8, which are captured from Fig. 5(b).

\section{Computer modeling of ionic diffusion in the ITZ}

The ionic diffusivity has been commonly measured as one of the critical indexes to be related to the durability for cementitious composites. Numerous experimental studies were thus performed to assess the ionic diffusivity of cementitious composites during past decades. Though fruitful achievements were obtained, some drawbacks were noticed as well. For instance, with respect to the long-term ponding test and the electrochemical acceleration test, the former is extremely time-consuming which does not meet practical requirements, while the latter appears to vary much among researchers (Sun et al. 2011). In these concerns, some analytical and numerical methods were thus developed to predict the ionic diffusivity of cementitious composites, such as the Maxwell equation and the random walk algorithm, which proved to favor a lot in engineering practices (Princigallo et al. 2003). Nevertheless, due to the fact that the ITZ is not a discrete phase within ce-

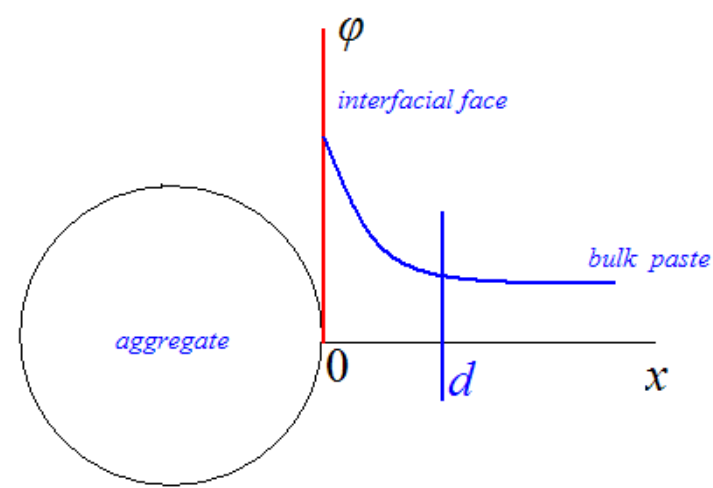

Fig. 7 Schematic show of the fitting equations for porosity profile.
Table 6 Fitting parameters for the mortar A2 based on the simulation results.

\begin{tabular}{rccc}
\hline$\varphi_{\text {if }}$ & $\varphi_{\text {bulk }}$ & $d$ & $\beta$ \\
\hline $59 \%$ & $27 \%$ & $14.9 \mu \mathrm{m}$ & 0.51 \\
\hline
\end{tabular}

mentitious composites, some priori values have to be assumed for the diffusivity of ITZ either testing or empirical. An assessment of the ionic diffusivity of ITZ from a structural basis is fairly necessary. Thus, in this study, with the simulated microstructures as inputs, the assessment of ionic diffusivity for ITZ and bulk paste is conducted based on a novel approach, i.e., the lattice Boltzmann method.

The lattice Boltzmann method can date back to the lattice gas model, i.e., one type of the cellular automaton based on the discrete particle kinetic for fluid flow. At present, it has been applied to explore various complex physical phenomena for cement based materials (Zalzale and McDonald 2012; Zhang et al. 2013). Herewith, we give some brief introductions on the implementation of lattice Boltzmann method.

The discrete Boltzmann equation that simulates the movement of particles (ions) under a certain concentration gradient is expressed as follows,

$$
\begin{aligned}
& f_{i}\left(r+e_{i} \cdot \delta t, t+\delta t\right)-f_{i}(r, t) \\
& =-\frac{1}{\tau}\left[f_{i}(r, t)-f_{i}^{e q}(r, t)\right]
\end{aligned}
$$

where $i$ denotes the direction of discrete velocity; $f_{i}$ and $f_{i}^{e q}$ is the non-equilibrium and the equilibrium number of particles with a discrete velocity $\boldsymbol{e}_{i}$ at space $\boldsymbol{r}$ and time $t$ after a lattice time $\delta t ; \tau$ is the relaxation time which is related to the speed of movement of particles.

In general, a three-dimensional problem requires 19 discrete velocities, i.e., D3Q19 (Chen et al. 1992). However, for the pure diffusive transport without convective term, 7 discrete velocities prove to be available without degrading the accuracy, i.e., D3Q7 (Xuan et al. 2010). Herewith, $f_{i}^{e q}$ and $\boldsymbol{e}_{i}$ are taken as follows,

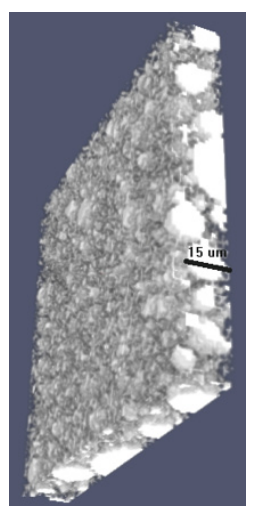

(a) ITZ-15 $\mu \mathrm{m}$

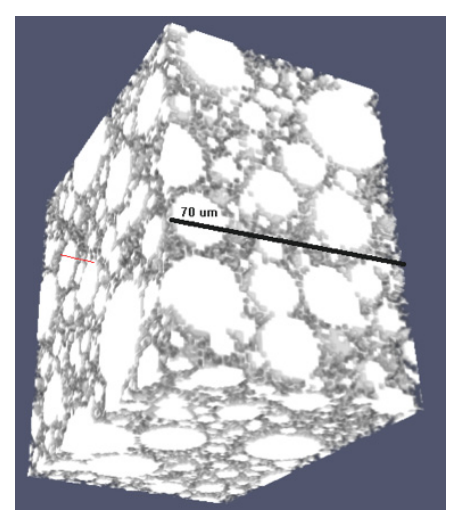

(b) bulk paste- $70 \mu \mathrm{m}$
Fig. 8 Discrete binary images of ITZ and bulk paste for the mortar A2, where white phases denote solid components. 


$$
\begin{aligned}
f_{i}^{e q} & =\frac{1}{7} C(\mathrm{r} ; t) \\
{\left[e_{i}\right] } & =c \cdot\left[\begin{array}{ccccccc}
0 & 1 & -1 & 0 & 0 & 0 & 0 \\
0 & 0 & 0 & 1 & -1 & 0 & 0 \\
0 & 0 & 0 & 0 & 0 & 1 & -1
\end{array}\right] ; c=\delta x / \delta t
\end{aligned}
$$

where $\delta x$ is the lattice spacing, and $C(\boldsymbol{r} ; t)$ is the ionic concentration which holds that

$$
C(r ; t)=\sum_{i} f_{i}
$$

Meanwhile, the relaxation time $\tau$ holds that

$$
D_{0}=\frac{2}{7}\left(\tau-\frac{1}{2}\right) \frac{(\delta x)^{2}}{\delta t}
$$

where $D_{0}$ is the ionic diffusion coefficient in bulk water.

The ionic flux along the diffusive direction is obtained via

$$
M=\sum_{i}\left(\mathrm{e}_{i} \cdot f_{i} \cdot \frac{\tau-0.5}{\tau}\right)
$$

The relative ionic diffusivity is defined that $D_{\text {eff }} / D_{0}=M / M_{0}$, where $M_{0}$ is the ionic flux in bulk water. In computer implementation, the ionic concentration at the inlet and outlet face is set to be constant 1 and 0 respectively, and periodic conditions are applied for other faces. The relaxation time $\tau$ is taken at 1. As shown in Fig. 9, ions diffuse only in pore nodes of ITZ and bulk paste, since solid nodes are assumed to be impermeable.

\section{Results and discussions}

\subsection{Effect of replacement levels of SCMs}

The component profiles of mortar series A are shown in Fig. 10. For mortars $\mathrm{A} 1, \mathrm{~A} 2$ and $\mathrm{A} 3$, the cement content is fixed at $60 \%$, while the slag content increases from $0 \%$, $20 \%$ to $40 \%$. The increasing slag content leads to the decreasing porosity. Meanwhile, when the slag content

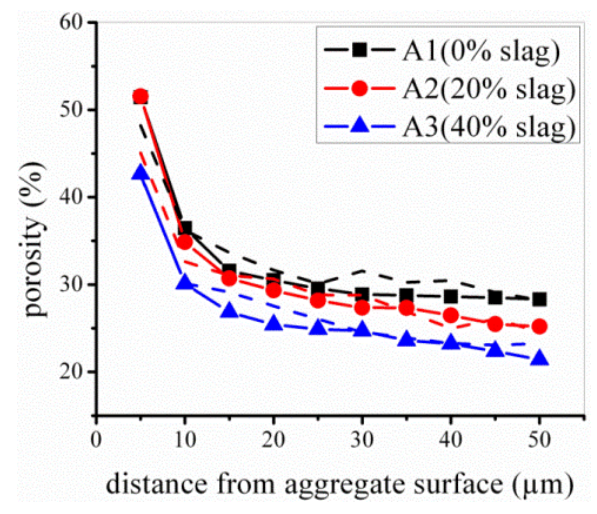

(a) Area fraction profile of capillary pores increases from $0 \%$ to $20 \%$, a more remarkable decrease of anhydrous fraction is detected, compared to that from $20 \%$ to $40 \%$. For the $0 \%$ slag content mortar (A1), most of the anhydrous grains are filler particles. As for the $40 \%$ slag content mortar (A3), the hydration of slag depends on the amount of calcium hydroxide produced by cement hydration, which leads to the anhydrous fraction comparable to mortar A2. As noted, when the slag content increases, the decrease of porosity is found to be lower compared to the decreasing anhydrous fraction. In other words, the decrease of anhydrous fraction does not result in an expected decrease of porosity, since the volume of hydration products is larger than the corresponding volume of reactants. In fact, as the slag content increases, the chemical compositions of hydration products change as well. For the $0 \%$ slag content (A1), hydration products contain considerable amount of calcium hydroxide which tends to precipitate in pore solution. The filling effect of hydration products, i.e., decreasing the volume of pore solution, is thus quite prominent. For the $40 \%$ slag content (A3), most of the released calcium hydroxide is consumed by slag. The hydration of slag produces calcium silicate hydrate, which mainly forms in the vicinity of anhydrous slag particles. The filling effect of decreasing porosity is thus not so prominent.

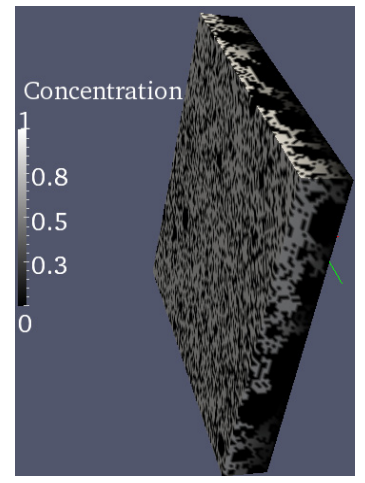

(a) ITZ

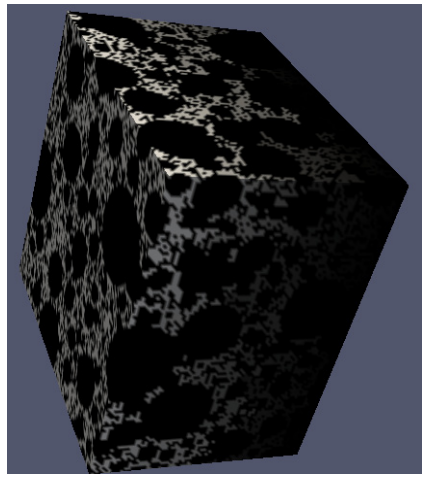

(b) Bulk paste
Fig. 9 Simulated ionic diffusion based on the lattice Boltzmann method.

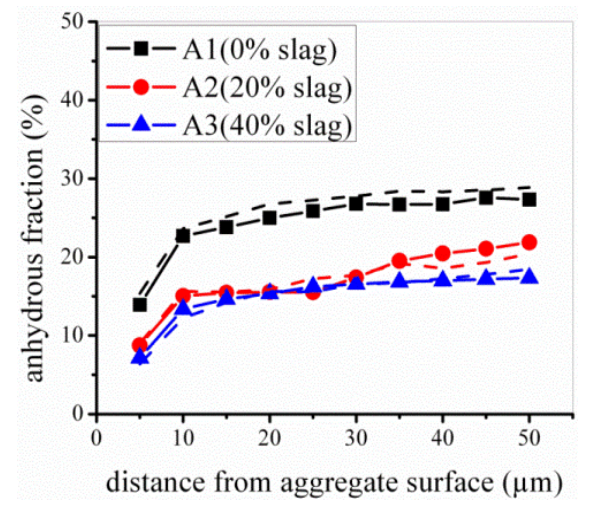

(b) Area fraction profile of anhydrous grains

Fig. 10 Component profiles of mortar series A, where dashed and solid lines are from BSE image analysis and numerical simulation respectively. 
Table 7 Extent $(d)$ and average porosity $\left(\varphi_{\text {ITZ }}\right)$ of ITZ for mortar series $\mathrm{A}$ fitted from the simulation results.

\begin{tabular}{cccc}
\hline Mortar & $\varphi_{\text {bulk }}$ & $\varphi_{\text {ITZ }}$ & $d$ \\
\hline A1 & $30 \%$ & $39 \%$ & $14.8 \mu \mathrm{m}$ \\
\hline A2 & $28 \%$ & $36 \%$ & $14.9 \mu \mathrm{m}$ \\
\hline A3 & $24 \%$ & $34 \%$ & $15.1 \mu \mathrm{m}$ \\
\hline
\end{tabular}

The ITZ extent can be fitted, with which the average area fractions of capillary pores and anhydrous grains for ITZ and bulk paste are further determined. Results are listed in Table 7. The ionic diffusivities of ITZ and bulk paste are assessed based on the lattice Boltzmann method As shown in Fig. 11, the ionic diffusivities decrease with the increasing replacement level of slag, where the decreasing magnitudes from $20 \%$ to $40 \%$ are larger than those from $0 \%$ to $20 \%$. In fact, as the replacement level of slag increases, more hydration products come from the hydration of slag, which turns out refining the pore structure.

\subsection{Effect of curing age}

The component profiles of mortar series B are shown in Fig. 12. As curing age increases, the microstructure turns to be denser. In fact, upon a longer curing age, the degree of hydration goes higher. The increasing filling effect of hydration products then leads to the decreasing porosity. As noted, when curing age increases from 28 days to 56 days, the decreasing magnitude of porosity is much lar-

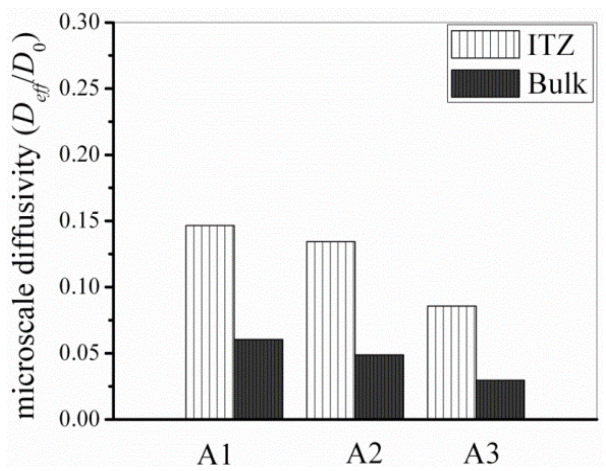

Fig. 11 Simulated ionic diffusivities of ITZ and bulk paste for mortar series $\mathrm{A}$.

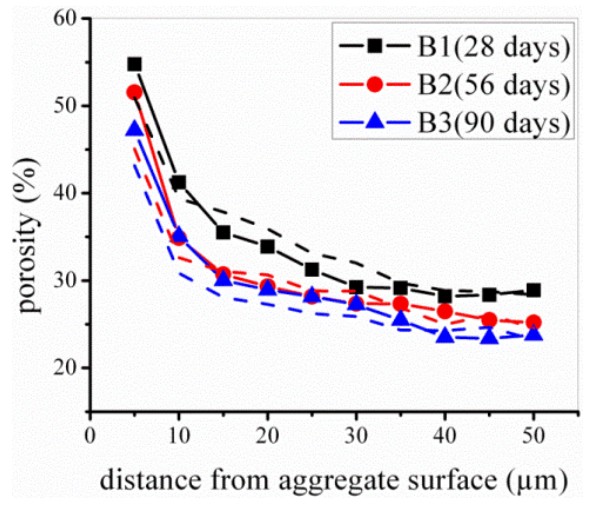

(a) Area fraction profile of capillary pores
Table 8 Extent $(d)$ and average porosity $\left(\varphi_{\text {ITZ }}\right)$ of ITZ for mortar series $B$ fitted from the simulation results.

\begin{tabular}{cccc}
\hline Mortar & $\varphi_{\text {bulk }}$ & $\varphi_{\text {ITZ }}$ & $d$ \\
\hline B1 & $31 \%$ & $43 \%$ & $17.6 \mu \mathrm{m}$ \\
\hline B2 & $28 \%$ & $36 \%$ & $14.9 \mu \mathrm{m}$ \\
\hline B3 & $25 \%$ & $34 \%$ & $14.8 \mu \mathrm{m}$ \\
\hline
\end{tabular}

ger, compared to that of the situation from 56 days to 90 days. For a plain cement system, most of the hydration is completed within curing age of 28 days. For the current ternary system, however, due to the delayed hydration of slag, the detectable hydration process lasts more than 56 days. Moreover, when curing age increases from 56 days to 90 days, the porosity in the very vicinity of aggregate surface, i.e., around $5 \mu \mathrm{m}$, sees no detectable drop. Compared to zones further out, the hydration process close to aggregate is faster. In particular, due to the wall effect, small binder grains are more often to pack in the vicinity of aggregate surface. A higher initial w/b ratio and the larger specific surface of binder grains lead to an accelerated hydration process.

As listed in Table 8, the ITZ extent displays a minor decrease when curing age increases. For the sake of comparison, the constant extent of ITZ is applied, i.e., 15 $\mu \mathrm{m}$. Thereafter, the ionic diffusivities of ITZ and bulk paste are assessed based on the lattice Boltzmann method. As shown in Fig. 13, the ionic diffusivities of ITZ and bulk paste decrease as curing age increases.

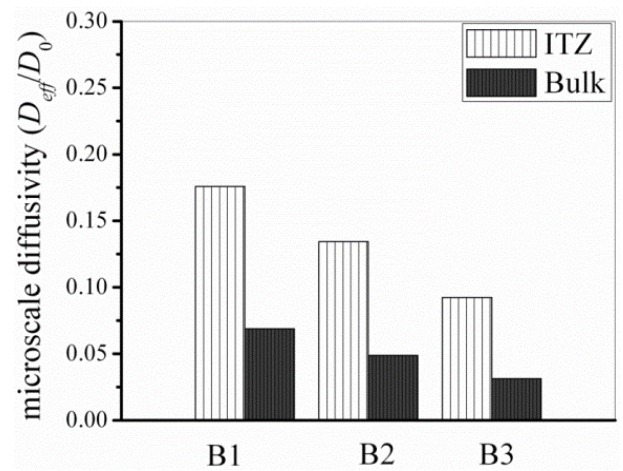

Fig. 13 Simulated ionic diffusivities of ITZ and bulk paste for mortar series $B$.

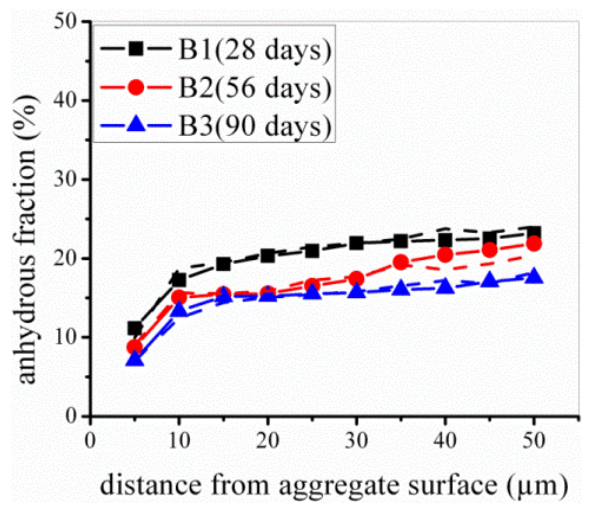

(b) Area fraction profile of anhydrous grains

Fig. 12 Component profiles of mortar series B, where dashed and solid lines are from BSE image analysis and numerical simulation respectively. 


\subsection{Effect of $w / b$ ratio}

The component profiles of mortar series $\mathrm{C}$ are shown in Fig. 14. It can be found that $\mathrm{w} / \mathrm{b}$ ratio is critical to the overall porosity level of cement paste. An increasing w/b ratio leads to an increasing porosity. Moreover, it appears that within the zones of distance larger than $15 \mu \mathrm{m}$ from aggregate surface, the increasing magnitude of porosity is larger when the $\mathrm{w} / \mathrm{b}$ ratio increases from 0.3 to 0.4 , compared to that of the situation from 0.4 to 0.5 . On the contrary, the zones of distance smaller than $15 \mu \mathrm{m}$ from aggregate surface, a linear relationship can be detected between porosity and $\mathrm{w} / \mathrm{b}$ ratio.

The fitted ITZ extents for mortar series $\mathrm{C}$ are listed in Table 9, where the average area fractions of capillary pores and anhydrous grains are presented as well. Similarly, the ionic diffusivities of ITZ and bulk paste are assessed based on the lattice Boltzmann method with a constant ITZ extent of $15 \mu \mathrm{m}$. As shown in Fig. 15, the ionic diffusivities of ITZ and bulk paste increase as $\mathrm{w} / \mathrm{b}$ ratio increases. Moreover, it can also be noted that the increasing magnitudes of ionic diffusivities are larger when $\mathrm{w} / \mathrm{b}$ ratio increases from 0.3 to 0.4 , compared to those from 0.4 to 0.5 .

\section{Concluding remarks}

In this paper, we present some results about the assessment of structural feature and ionic diffusivity of ITZ in blended cementitious composites, which are made of Portland cement, blast furnace slag and limestone filler. In particular, the structural feature of ITZ is investigated by means of a combination of experimental measurement and numerical simulation, i.e., the BSE image analysis and the HYMOSTRUC model. Thereafter, based on the lattice Boltzmann method, the ionic diffusion is modeled in simulated microstructures of ITZ and bulk paste. It is confirmed that casting factors are of significant importance to influence the ITZ. Some conclusions can be drawn as follows,

(1) The ITZ extent is almost constant with respect to varying replacement levels of SCMs, curing age and $\mathrm{w} / \mathrm{b}$ ratio. However, the average porosity of ITZ is

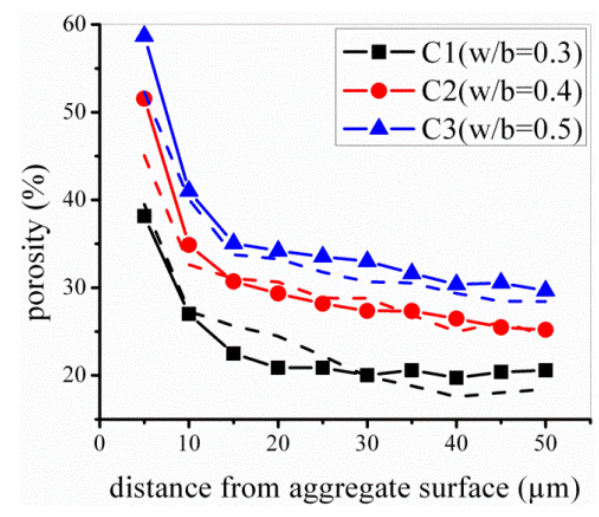

(a) Area fraction profile of capillary pores
Table 9 Extent $(d)$ and average porosity $\left(\varphi_{\text {ITZ }}\right)$ of ITZ for mortar series $\mathrm{C}$ fitted from the simulation results.

\begin{tabular}{cccc}
\hline Mortar & $\varphi_{\text {bulk }}$ & $\varphi_{I T Z}$ & $d$ \\
\hline $\mathrm{C} 1$ & $20 \%$ & $31 \%$ & $14.8 \mu \mathrm{m}$ \\
\hline $\mathrm{C} 2$ & $28 \%$ & $36 \%$ & $14.9 \mu \mathrm{m}$ \\
\hline $\mathrm{C} 3$ & $30 \%$ & $42 \%$ & $14.7 \mu \mathrm{m}$ \\
\hline
\end{tabular}

significantly influenced by these casting factors. In particular, either an increasing replacement level of reactive SCMs, an increasing curing age or a decreasing $\mathrm{w} / \mathrm{b}$ ratio results in the decreasing porosity.

(2) The ionic diffusivity of ITZ is significantly influenced by replacement levels of SCMs, curing age and $w / b$ ratio. In particular, either an increasing replacement level of reactive SCMs, an increasing curing age or a decreasing $\mathrm{w} / \mathrm{b}$ ratio results in the decreasing ionic diffusivity.

It is worthy to note that the designed mortars in this study are fixed with a constant aggregate content of $10 \%$ vol., which simplifies the reality a lot. Though it allows a much clearer discussion of replacement levels of SCMs, curing age and w/b ratio, some effects such as compaction and water adsorption have been underestimated, which might be prominent in real concretes. Besides that, for the assessment of ionic diffusivity, the influence of chemical binding has been neglected.

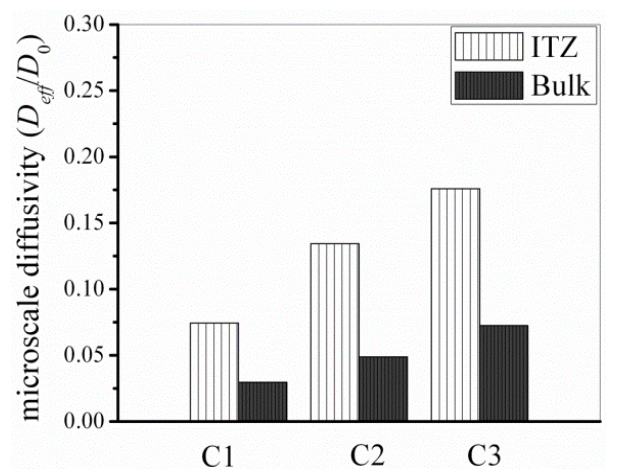

Fig. 15 Simulated ionic diffusivities of ITZ and bulk paste for mortar series $\mathrm{C}$.

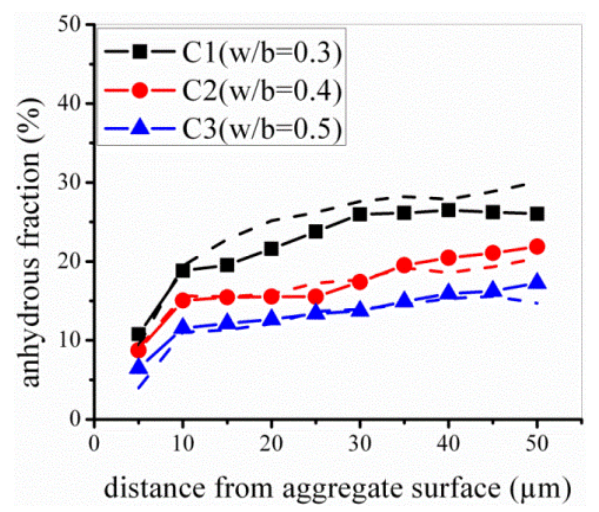

(b) Area fraction profile of anhydrous grains

Fig. 14 Component profiles of mortar series C, where dashed and solid lines are from BSE image analysis and numerical simulation respectively. 


\section{Acknowledgements}

The authors gratefully acknowledge the financial support from the China Scholarship Council (CSC), the Fundamental Research Funds for the Central Universities and the China Railway Corporation under Grant No. 2013G001-A-2.

\section{References}

Aligizaki, K. K., (2006). "Pore structure of cement-based materials." Taylor \& Francis, Oxon, UK.

Chen, S., Wang, Z., Shan, X. W. and Doolen, G. D., (1992). "Lattice Boltzmann computational fluid dynamics in three dimensions." Journal of Statistical Physics, 68, 379-400.

Gao, J. M., Qian, C. X., Liu, H. F., Wang, B. and Li, L., (2005). "ITZ microstructure of concrete containing GGBS." Cement and Concrete Research, 35, 1299-1304.

Gao, Y., De Schutter, G., Ye, G., Huang, H. L., Tan, Z. J. and Wu, K., (2013a). "Characterization of ITZ in ternary blended cementitious composites: Experiment and simulation." Construction and Building Materials, 41, 742-750.

Gao, Y., De Schutter, G., Ye, G., Huang, H. L., Tan, Z. J. and $\mathrm{Wu}, \mathrm{K}$. , (2013). "Porosity characterization of ITZ in cementitious composites: Concentric expansion and overflow criterion." Construction and Building Materials, 38, 1051-1057.

Gao, Y., De Schutter, G., Ye, G., Tan, Z. J. and Wu, K., (2014). "The ITZ microstructure, thickness and porosity in blended cementitious composite: Effects of curing age, water to binder ratio and aggregate content." Composites Part B: Engineering, 60, 1-13.

Huang, H. L. and Ye, G. (2012), "Simulation of self-healing by further hydration in cementitious materials" Cement and Concrete Composites, 34, 460-467.

Lothenbach, B., Scrivener, K. and Hooton, R. D., (2011). "Supplementary cementitious materials." Cement and Concrete Research, 41, 1244-1256.

Luan, Y., Ishida, T., Nawa, T. and Sagawa, T., (2012), "Enhanced model and simulation of hydration process of blast furnace slag in blended cement." Journal of Advanced Concrete Technology, 10(1), 1-13.

Lutz, M. P., Monteiro, P. J. M. and Zimmerman, R. W., (1997). "Inhomogeneous interfacial transition zone model for the bulk modulus of mortar." Cement and Concrete Research, 27(7), 1113-1122.

Maekawa, K., Ishida, T. and Kishi, T., (2003). "Multiscale modeling of concrete performance integrated material and structural mechanics." Journal of Advanced Concrete Technology, 1(2), 91-126.

Maekawa, K., Ishida, T. and Kishi, T., (2009). "Multi-scale modeling of structural concrete." Taylor \& Francis, Oxon, UK.

Mehta, P. K. (1998). "Role of pozzolanic and cementitious materials in sustainable development of the concrete industry." American Concrete Institute
Special Publication, 178, 1-20.

Osborne, G. J., (1999). "Durability of Portland blast-furnace slag cement concrete." Cement and Concrete Composites, 21, 11-21.

Princigallo, A., van Breugel, K. and Levita, G., (2003). "Influence of the aggregate on the electrical conductivity of Portland cement concretes." Cement and Concrete Research, 33, 1755-1763.

Prokopski, G. and Halbiniak, J., (2000). "Interfacial transition zone in cementitious materials." Cement and Concrete Research, 30, 579-583.

Richardson, I. G. (2008). "The calcium silicate hydrates." Cement and Concrete Research, 38(2), 137-158.

Saeki, T. and Monteiro, P. J. M., (2005). "A model to predict the amount of calcium hydroxide in concrete containing mineral admixture." Cement and Concrete Research, 35, 1914-1921.

Scrivener, K., Crumbie, A.K. and Laugesen, P., (2004). "The interfacial transition zone (ITZ) between cement paste and aggregate in concrete." Interface Science, 12, 411-421.

Shannag, M. J. (2000). "High strength concrete containing natural pozzolan and silica fume." Cement and Concrete Composites, 22, 399-406.

Sun, G. W., Zhang, Y. S., Sun, W., Liu, Z. Y. and Wang, C. H., (2011), "Multi-scale prediction of the effective chloride diffusion coefficient of concrete." Construction and Building Materials, 25, 3820-3831.

van Breugel, K., (1991). "Simulation of hydration and formation of structure in hardening cement-based materials." $\mathrm{PhD}$ Thesis, Delft University of Technology.

Xuan, Y. M., Zhao, K. and Li, Q., (2010). "Investigation on mass diffusion process in porous media based on Lattice Boltzmann method." Heat Mass Transfer, 46, 1039-1051.

Ye, G. and van Breugel, K., (2009). "Simulation of connectivity of capillary porosity in hardening cement-based systems made of blended materials." Heron, 54(2/3), 161-182.

Yoon, Y. S., Won, J. P., Woo, S. K. and Song, Y. C., (2002). "Enhanced durability performance of fly ash concrete for concrete-faced rockfill dam application." Cement and Concrete Research, 32, 23-30.

Zalzale, M. and McDonald, P. J., (2012). "Lattice Boltzmann simulations of the permeability and capillary adsorption of cement model microstructures." Cement and Concrete Research, 42, 1601-1610.

Zhang, M. Z., Ye, G. and van Breugel, K., (2012). "Modeling of ionic diffusivity in non-saturated cement-based materials using lattice Boltzmann method." Cement and Concrete Research, 42, 1524-1533.

Zhou, J., (2011), "Performance of engineered cementitious composites for cncrete repairs." $\mathrm{PhD}$ thesis, Delft University of Technology, Delft, the Netherlands. 